\title{
UM GRUPO DE PESQUISA NA EDUCAÇÃO BÁSICA: Distanciamentos e Aproximações com Princípios da Iniciação Científica
}

\author{
Sandra Aparecida dos Santos ${ }^{1}$ \\ Marcus Eduardo Maciel Ribeiro ${ }^{2}$ \\ Michelle Câmara Pizzato ${ }^{3}$
}

\begin{abstract}
RESUMO
O estudo de um grupo de pesquisa, formado por estudantes do Ensino Fundamental e Ensino Médio, em uma escola da rede privada no município de Rio do Sul - SC, pode subsidiar a reflexão sobre a institucionalização da Iniciação Científica (IC) no Brasil e suas contribuições para o desenvolvimento de conceitos e atitudes científicas nos estudantes participantes. As metodologias utilizadas foram a pesquisa bibliográfica e a observação participante, com os dados coletados sendo tratados por análise de conteúdo, da qual emergiram duas unidades de análise: distanciamentos e aproximações entre o grupo de pesquisa e princípios da Iniciação Científica institucionalizada no Brasil. Os dados revelaram que há distanciamentos e aproximações do grupo em relação à IC, tanto na ênfase quanto nas concepções de ambos, mostrando-se o distanciamento maior em relação às concepções. Em sua especificidade, a ênfase e as concepções do grupo contribuem positivamente para a realização das pesquisas planejadas.
\end{abstract}

Palavras-chave: Educação básica. Iniciação científica. Grupo de pesquisa.

A RESEARCH GROUP IN ELEMENTARY SCHOOL:

DISTANCING AND APPROACHMENT WITH PRINCIPLES OF SCIENTIFIC INITIATION

\begin{abstract}
A research group made of Elementary and High School students of a private school located in Rio do Sul (SC) could experience the contribution and acts provided by the Scientific Research - SR - in Brazil. The data was collected from bibliography researches and observation. For better analysis, this group was split into two: distancing and approachment among the SR group and principles of the SR institutionalized in Brazil. The data shows there are distancing and approachment in this group when it goes to concept and the activities themselves, however the greater is the distancing in the conceptions. It is easy to agree that these activities and conceptions contribute positively to accomplish the scheduled researches.
\end{abstract}

Keywords: Elementary school. Scientific research. Search group.

Recebido em: 8/6/2019

Aceito em: 5/11/2019

\footnotetext{
Doutora em Educação em Ciências: química da vida e saúde pela Universidade Federal do Rio Grande do Sul (2020). Professora do Centro Universitário para o Desenvolvimento do Alto Vale do Itajaí - SC. http://lattes.cnpq.br/3678692075804001. https://orcid.org/0000-00032827-6300. esasandra@unidavi.edu.br

2 Doutorado em Educação em Ciências e Matemática pela Pontifícia Universidade Católica do Rio Grande do Sul (2017). Professor do Instituto Federal Sul-Rio-Grandense de Educação, Ciência e Tecnologia. http://lattes.cnpq.br/5628561909586804. https://orcid.org/00000001-5974-3050.profmarcus@yahoo.com.br

3 Graduação em Química - Licenciatura - pela Universidade Federal do Rio Grande do Sul (1998). Mestrado em Ensino de Ciências (Modalidade Química) pela Universidade de São Paulo (2002). Doutorado em Ensino de Ciências pela Universidad de Burgos (2010). Professora do Instituto Federal de Educação, Ciência e Tecnologia do Rio Grande do Sul, Campus Porto Alegre. Tem experiência na área de Educação em Ciências, com ênfase em Didática e Epistemologia das Ciências, atuando principalmente nos seguintes temas: formação de professores, ensino de Química, educação profissional e tecnológica, história e filosofia das ciências e concepções e práticas docentes. http://lattes.cnpq.br/6630822945379310. https://orcid.org/0000-0002-3394-1179. michelle.pizzato@poa.ifrs.edu.br
} 
A necessidade de uma Educação Básica de qualidade tem como pressuposto a formação de cidadãos críticos e conscientes da sua prática no desenvolvimento de um país igualitário e cientificamente desenvolvido. Para pensar a qualidade da educação faz-se necessário considerar dimensões intra e extraescolares, ponderando o grande e complexo desafio que se constitui. Pesquisas acerca das dimensões, dos parâmetros e critérios que qualificam a educação vêm ganhando importância e elucidando o processo de melhoria no tocante a uma aprendizagem mais efetiva (DOURADO; OLIVEIRA, 2009; GADOTTI, 2013).

Desse modo, entende-se que investigações a respeito da pesquisa, como princípio pedagógico, têm como objetivo protagonizar o estudante e oferecer sentido ao tema estudado. Também permitem o desenvolvimento do conhecimento e de atitudes científicas a ele relacionados, mostrando-se relevantes na comunidade acadêmica, uma vez que promovem a reflexão qualificada sobre as proposições metodológicas, da elaboração epistêmica de ensino, de aprendizagem e de educação que, por consequência, poderão provocar modificações significativas nos currículos da área das Ciências da Natureza.

A pesquisa, como princípio pedagógico, ganha espaço nas discussões sobre o Ensino das Ciências por meio de diferentes abordagens didáticas e metodológicas (CACHAPUZ; PRAIA; JORGE, 2000; DEMO, 2001; MORAES; RAMOS; GALIAZZI, 2004; VILCHES et al.,2007), bem como pela legitimidade em documentos oficiais, como as Diretrizes Curriculares Nacionais Gerais para a Educação Básica (Resolução no 4, de 13 de julho de 2010) e as Diretrizes Curriculares Nacionais para o Ensino Médio (Resolução no 2, de 30 de janeiro de 2012).

Nesse sentido, as pesquisas sobre ensino das ciências ganharam espaço, promovendo debates que emergiram com o desenvolvimento de diferentes projetos políticos e sociais coerentes com os períodos históricos, de modo a suscitar alterações nos currículos para a Educação Básica que resultem num ensino menos linear e com maior protagonismo dos estudantes.

Acredita-se, também, que a abordagem contextualizada e interdisciplinar dos conceitos referentes à área das Ciências da Natureza, favorece o (re)conhecimento e observação de situações reais por parte dos alunos, interferindo diretamente em seu ciclo social e cultural, de modo a qualificar suas escolhas e agir de forma mais justa e solidária no mundo em que estão inseridos.

A partir dessas constatações pretende-se estudar as contribuições para o desenvolvimento de conceitos e atitudes científicas em estudantes do Ensino Fundamental (EF) e Ensino Médio (EM), participantes do Grupo Estudantil de Iniciação Científica (Geic), em uma escola de Educação Básica da rede privada no município de Rio do Sul - SC, o qual se apresenta como um grupo inovador e multisseriado, no contraturno às aulas curriculares. Para tanto é importante que se investiguem as questões que mostram distanciamentos e aproximações que este grupo apresenta em relação à Iniciação Científica (IC) institucionalizada no Brasil, gerando questões que subsidiarão sua definição e continuidade, como: Os procedimentos realizados no Geic estão de acordo com os princípios da IC? Contribuem positivamente para a realização das pesquisas planejadas? 
A investigação destes questionamentos permitirá a compreensão do grupo em questão, sua constituição, criação e desenvolvimento. Dessa forma, este trabalho apresenta informações sobre a IC no Brasil historicamente, a IC na Educação Básica, em particular no EM, e um panorama do Geic. A metodologia do trabalho consistiu em pesquisa bibliográfica e observação participante, culminando na análise e discussão dos dados por meio de análise de conteúdo.

\section{A INICIAÇÃO CIENTÍFICA NO BRASIL: UM OLHAR DESDE SUA HISTÓRIA}

Historicamente, o desenvolvimento científico e tecnológico tem seu percurso ligado ao percurso do desenvolvimento econômico e social. No Brasil, a história confirma-se e em 15 de janeiro de 1951 a Lei 1.310 criou o Conselho Nacional de Pesquisa - CNPq - hoje denominado Conselho Nacional de Desenvolvimento Científico e Tecnológico, entidade governamental, com as finalidades de

[...] promover e estimular o desenvolvimento da investigação científica e tecnológica, mediante a concessão de recursos para pesquisa, formação de pesquisadores e técnicos, cooperação com as universidades brasileiras e intercâmbio com instituições estrangeiras. A missão do CNPq era ampla, uma espécie de "estado-maior da ciência, da técnica e da indústria, capaz de traçar rumos seguros aos trabalhos de pesquisas" científicas e tecnológicas do país, desenvolvendo-os e coordenando-os de modo sistemático (BRASIL, 1951).

Em vigência até os dias atuais, o CNPq fomenta programas institucionais científicos, tanto para estudantes do $\mathrm{EF}_{\text {e }} \mathrm{EM}^{4}$ quanto do Ensino Superior, por meio de bolsas de IC. É importante citar que, segundo Souza e Filipecki (2017, p. 77), "A institucionalização do termo iniciação científica no Brasil acompanha a consolidação da pesquisa nacional, que tem como um dos seus marcos a criação do CNPq, em 1951."

Desde a década de 80 há uma intensificação do incentivo à IC, como um programa na Graduação, com o intuito de reduzir o tempo de formação do pesquisador, ou seja, iniciar o mais precocemente possível a formação de profissionais para a área da ciência e tecnologia, considerando o contexto social e econômico que vem despontando nos processos de produção de bens e serviços e nas relações sociais (ZAKON, 1989; NEVES, 2001; TENÓRIO; BERALDI, 2010).

A década de 90 caracteriza-se pela fase da valorização da IC, revelando um crescimento significativo no número de bolsas fomentadas pelo CNPq, fase esta definida por Martins e Martins (1999) como o "Período da Iniciação Científica".

Cabe citar que mesmo antes da institucionalização da IC em âmbito nacional com a criação do CNPq nas décadas de 40 e 50, já existia de fato e de forma incipiente a atividade de pesquisa por "estudantes ajudantes" (BARIANI, 1998).

$\mathrm{Na}$ intenção de elucidar o entendimento sobre o conceito de IC, Bridi (2015, p. 13) faz menção à denominação destacando que se refere "[...] a uma atividade que inicia o aluno de graduação na produção de conhecimento científico. Com isso, tal atividade faz

4 No Brasil, os Ensinos Fundamental (EF) e Médio (EM) consistem em níveis subsequentes da Educação Básica, sendo o EM constituído por três anos letivos e antecessor do Ensino Superior. 
sentido em uma estruturação de ensino superior que inclui em suas práticas acadêmicas a pesquisa científica". Essa atividade é apresentada por Zakon (1989, p. 868) a partir de "[...] três faces: o aluno, o orientador e as condições de trabalho".

A IC, como programa desenvolvido para os estudantes do Ensino Superior, vem sendo alvo de pesquisas em diversas áreas do saber, revelando convergência para o potencial de desenvolvimento da capacidade criativa dos participantes e para a aproximação destes com a natureza da ciência (QUEIROZ; ALMEIDA, 2004; SILVA JUNIOR et al., 2014).

Com o olhar para a IC no Ensino Superior caracterizam-na Silva Junior et al. (2014), como o processo que

[...] permite que o aluno de graduação tenha noções teóricas e metodológicas de pesquisa, buscando incentivar-Ihe a capacidade de pensar e o espírito questionador. [...] Além disso, a atividade de pesquisa na graduação é importante para desenvolver o espírito crítico e a competência para buscar respostas aos problemas da prática profissional (p. 327).

Nesse contexto, algumas vantagens e desvantagens da IC são apontadas. Entre as vantagens, cabe citar o papel complementar de melhoria da análise crítica do estudante que participa, assim como maturidade intelectual, compreensão da ciência e possibilidades futuras, por meio das relações que estabelece, tanto acadêmicas como profissionais, além da possibilidade de auxílio financeiro, na condição de bolsistas (BARROS; SOUZA; MACHADO, 2012). Uma vantagem para o professor orientador é a possibilidade de aumentar sua produtividade, ou seja, o número de trabalhos publicados (TENÓRIO; BERALDI, 2010).

Considerando, ainda, as contribuições advindas da realização da IC, Massi e Queiroz $(2012$, p. 272) indicam o contato dos estudantes "[...] com as diversas formas de veiculação dos conteúdos científicos". Argumentam que "[...] esse contato pode vir a favorecer a apropriação da linguagem científica [...] e, consequentemente, o desenvolvimento de suas habilidades de comunicação oral e escrita no campo científico".

Um aspecto potencializado pela proposição da IC, apresentado por Mazon e Trevizan (2001), é a interdisciplinaridade. Observam que essa vinculação "[...] permite a construção ou reconstrução do conhecimento, através da ação conjunta de profissionais de diferentes áreas, possibilitando a desenvoltura da integração dos especialistas" (p. 86).

Quando o estudante é sujeito de um processo formativo no qual o ensino está atrelado à pesquisa, pautado na ciência e nos pressupostos investigativos, este adquire uma postura mais ativa; sobre a qual Coelho Filho e Gonzaga (2013) comentam que,

[...] à medida que os sujeitos tornam-se agentes do seu próprio processo formativo, centrando-se em uma formação pautada na pesquisa e nos pressupostos epistemológicos, bem como nos procedimentos que fundamentam as investigações científicas, sensibilizam-se para a importância da produção, e não da reprodução de conhecimentos científicos (p. 23). 
Entre os aspectos frágeis da IC, é apontada a relação com o orientador, uma escolha que deveria sempre ser pautada na contribuição real para o crescimento pessoal e intelectual, além da percepção não ingênua quanto ao sistema científico, a atenção a fraudes e egos que podem turvar a ênfase na Ciência, foco de um programa de IC (MASSI; QUEIROZ, 2015). Embora haja diretrizes oficiais para o desenvolvimento da IC, o trabalho é determinado, geralmente, pelo orientador, o que faz com que os alunos nem sempre participem de todas as etapas de realização de uma pesquisa científica (CARVALHO, 2002).

Ainda, com vistas a essa relação do orientador-orientado, Erdmann et al. (2011, p. 261), asseveram que a experiência de "Ser orientador pesquisador formador de recursos humanos em pesquisa desde a IC, requer competências pedagógicas, instrumentais, gerenciais e políticas de investigação [...]".

As críticas da pequena abrangência do programa, considerado selecionador e elitista, e o pequeno número de professores e acadêmicos envolvidos com pesquisa nas Instituições de Ensino Superior, tanto públicas quanto privadas, tornam-se constantes em relação à IC (MASSI; QUEIROZ, 2010).

Massi e Queiroz (2015) destacam que, no Brasil, a IC pode ser entendida sob duas perspectivas:

1) enquanto um processo que abarca todas as experiências vivenciadas pelos alunos - programas de treinamento, desenvolvimento de estudos sobre metodologia científica (dentro de uma disciplina ou não), visitas programadas a institutos de pesquisa e a indústrias, etc. - durante ou anterior à graduação, com o objetivo de promover o seu desenvolvimento com a pesquisa e, consequentemente, desenvolver a chamada formação científica; 2 ) como o desenvolvimento de um projeto de pesquisa elaborado e desenvolvido sob orientação de um docente da universidade, realizada com ou sem bolsa para os alunos (p. 37).

Apesar do considerável número de estudantes do Ensino Superior desenvolvendo esse tipo de atividade no país, pesquisas sobre IC não são numerosas no Brasil; como consequência, o conhecimento produzido sobre o assunto é escasso e difuso (QUEIROZ; ALMEIDA, 2004; MASSI; QUEIROZ, 2010). Se esse é o quadro para o Ensino Superior, para a Educação Básica é muito mais frágil, uma vez que não é uma prática comum nas instituições de ensino desse nível.

As pesquisas apontam características inerentes e/ou desejáveis para a IC, e entre elas torna-se importante citar: 1 ) a efetivação entre o ensino e a pesquisa (BREGALIA, 2002; BRIDI, 2004); 2) a motivação do estudante na sala de aula, pela construção de significados de conceitos e teorias (AGUIAR, 1997; BREGLIA , 2002); 3) o "despertar" de qualidades/habilidades para a futura vida profissional (PIRES, 2002; FIOR, 2003); 4) desenvolvimento da autonomia (BAZIN, 1983); 5) a promoção da autovalorização e autoestima do estudante (PIRES, 2002); 6) a compreensão do "fazer ciência" (AGUIAR, 1997; QUEIROZ; ALMEIDA, 2004); 7) a socialização profissional, por meio das relações com o orientador e demais pesquisadores, assim como pela publicação dos trabalhos desenvolvidos (AGUIAR, 1997; TENÓRIO; BERALDI, 2010); 8) o encaminhamento do participante para a vida acadêmica (CARVALHO, 2002; BRIDI, 2004; CABRERO; COSTA; HAYASHI, 2006). 
A IC apresentada nas pesquisas desenvolvidas envolve certo grau de vivência nos laboratórios, como locais de produção da ciência, das mais diversas naturezas, laboratórios da área química, de espectrometria de massas a produtos naturais; da Biologia, de microbiologia à zoologia, a biotérios; das Engenharias, laboratórios de materiais a estúdios de projetos. Um dos referenciais para análise desse fazer ciência em "laboratórios", assim como neste trabalho, é o estudo realizado por Latour e Woolgar (1997), expresso no livro $A$ vida de laboratório: a produção dos fatos científicos.

A partir dessa análise é possível identificar componentes desse fazer ciência, como as partes do laboratório: $A$ (escritório, produção literária, escrita, leitura dos feitos científicos) e B (bancadas, equipamentos); a presença formal de orientadores e coorientadores para as pesquisas a serem desenvolvidas de forma compartilhada (pesquisas que se complementam contribuindo para a pesquisa do orientador, na maioria das vezes - 0 reconhecimento de uma hierarquia vigente), com papéis de orientações dirigidas, que autorizam ou redirecionam; a produção de documentos, culminando em registros sistemáticos na forma de relatórios para produção de posteriores artigos, ambos formais (uma série de diálogos, argumentação e fatos ficam omitidos nesses escritos); as regras e atitudes padronizadas.

Os estudantes participantes da IC apresentam melhor rendimento nos cursos de Graduação (AGUIAR, 1997; PIRES, 2002; BRIDI, 2004), além de indicarem que antes da participação, desconheciam o ambiente da ciência e possuíam concepções distorcidas sobre ela (AGUIAR, 1997).

\section{A INICIAÇÃO CIENTÍFICA NO ENSINO MÉDIO}

Culturalmente, a estrutura das escolas de Educação Básica, no Brasil, são "escolas de ensino", mesmo com tantas pesquisas apontando metodologias que protagonizam o estudante no processo de ensino e de aprendizagem, indicando que contribui efetivamente para a construção do conhecimento, uma "escola de ensino e pesquisa". "[...] o desenvolvimento de abordagens pedagógicas inovadoras que reconheçam a relação necessária entre trabalho(s), juventude(s), cultura(s) e ciência institui um verdadeiro desafio" (ARANTES; PERES, 2015, p. 39).

A IC no EM teve seu marco em 1986, pela criação do Programa de Vocação Científica (Provoc) da Escola Politécnica de Saúde Joaquim Venâncio (EPSJV) da Fundação Oswaldo Cruz (Fiocruz-RJ), por meio de metodologia participativa em locais formais de pesquisa no Brasil.

O Provoc foi descentralizado para outros Estados e instituições de Ensino Superior e pesquisa, em 1996, servindo de modelo para outros projetos posteriormente elaborados e propostos.

Os Programas de IC focados no EM, segundo Arantes e Peres (2015),

[...] são configurados como política pública educacional, institucionalizada e financiada principalmente pelo Estado, integrando as políticas públicas de educação científica e inclusão social das juventudes. Subvertendo o modelo pedagógico tradicional, a metodologia dos Programas de IC/EM consiste na participação ativa de jovens oriundos das redes públicas e privada, da educação básica e tecnológica, 
com disponibilidade integral para os estudantes, no cotidiano dos contextos formais de pesquisa e tecnológicos, sob a orientação de pesquisadores qualificados (p. 39).

Embora os discursos sobre a IC no EM contemplem documentos oficiais referentes a este nível de ensino e assumam uma postura pedagógica condizente, na prática os programas e iniciativas reproduzem a essência da IC pensada e proposta para o Ensino Superior, resguardadas algumas especificidades (ROSA, 2013).

Entre os aspectos considerados pode-se citar as escolhas profissionais prévias, a "escolha das carreiras" (MARANHÃO, 2011; MORAES et al., 2013), os processos seletivos que classificam os candidatos mediante critérios de seleção predeterminados (análise de documentos, entrevistas, análise de redação, entre outros), composição do comitê gestor, o papel do orientador - seus potenciais e fragilidades (FERREIRA, C. A., 2003, 2010; SANTOS; ABREU, 2011), o acesso a bolsas e recursos que viabilizem a participação do estudante.

Nesse contexto, Ferreira, C. A. (2010, p. 232) destaca a importância da consideração acerca de que "[...] fazer iniciação científica com alunos e alunas do Ensino Médio não é o mesmo que realizá-la com estudantes de Graduação". Mesmo que as políticas públicas indiquem especificidades referentes ao EM, as pesquisas indicam que não são tão óbvias pela comunidade universitária e demais sujeitos envolvidos.

Uma metodologia de avaliação para programas de IC em nível médio foi proposta por Ohayon et al. (2007), visando ao Programa de IC do Colégio de Aplicação da Universidade Federal do Rio de Janeiro - UFRJ. Os autores pretenderam "[...] contribuir com a consolidação de programas cujo perfil esteja afinado com a preparação de jovens pesquisadores, o que nos levou a apresentar indicadores avaliativos que possam auxiliar seu aprimoramento qualitativo" (OHAYON et al., 2007, p. 128).

As variáveis consideradas para elaboração dos indicadores estão de acordo com a proposição da IC no Brasil, estando previstos nos moldes da IC para o Ensino Superior.

A situação do EM brasileiro foi discutida por Martins (2012) quando a autora analisou as perspectivas de pesquisadores, professores e estudantes do EM participantes de Programa de IC, tratando-se do Núcleo de IC Júnior do Colégio de Aplicação da UFRJ. Segundo Martins (2012, p. 151-152), os Programas de IC oferecidos a estudantes do EM "[...] seguem o modelo da iniciação científica oferecida na graduação universitária e se desenvolvem em unidades de pesquisa que desfrutam de condições diferenciadas de estrutura de trabalho [...]".

O tema da orientação acadêmica de estudantes do EM está entre as pesquisas desenvolvidas acerca desse nível de ensino. Foi abordada por Ferreira (2003) e Filipecki, Barros e Elia (2006) a orientação acadêmica no Provoc, a partir dos olhares dos pesquisadores-orientadores do respectivo Programa. Esse tema foi pesquisado por Souza (2014), que analisou o agir docente na orientação de estudantes de Ensino Médio Técnico Integrado, no Instituto Federal de Goiás em atividades de IC, sob o viés dos estudos socioculturais e de letramentos. 
Na pesquisa desenvolvida por Oliveira (2017, p. 73) houve a detecção de que, além da proposição da IC no EM como programa institucional, “[...] a partir de 2001, a Iniciação Científica foi inserida no Ensino Médio em algumas escolas como componente curricular e que, em 2003, foi instituída como política pública pelo CNPq, como programa de bolsas para estudantes do Ensino Médio".

Como componente curricular e nominada a IC foi identificada no EM do Instituto Federal Catarinense - IFC - e da EPSJV/Fiocruz (OLIVEIRA, 2017). Dessa forma a IC está proposta no Brasil por meio dos formatos de Programa Institucional, política pública ${ }^{5}$ (a partir de 2003, com a criação da ICJ, pelo CNPq) ou componente curricular.

Como Programa Institucional,

[...] compreendem-se os programas de Institutos de Pesquisa ou Universidade que abrem as portas para estudantes da Educação Básica, geralmente de escolas públicas, para desenvolver Iniciação Científica com recursos das próprias instituições, geralmente instituições de ensino superior ou instituições de pesquisa. Há vários programas dessa natureza no Brasil e com compreensões diferenciadas com relação à sua prática na Educação Básica (OLIVEIRA, 2017, p. 74).

São inúmeros os Programas Institucionais de IC para o EM no Brasil, além dos já citados. Exemplifica esse formato de proposição para a IC o Programa de IC no EM: um Modelo de Aproximação da Escola com a Universidade Federal do Rio Grande do Sul UFRGS - e Secretaria de Educação do Estado (HECK et al., 2012).

\section{A INICIAÇÃO CIENTÍFICA COMO ATIVIDADE EXTRACURRICULAR PARA O EF E EM - O GRUPO ESTUDANTIL DE INICIAÇÃO CIENTÍFICA (GEIC)}

Em 2008, em uma escola da rede particular de ensino no município de Rio do Sul-SC, por iniciativa de duas professoras de Química e Biologia, para o EM, formou-se um grupo por afinidade à área das Ciências da Natureza, incluindo oito estudantes do 20 e 3 은 ano, visando a estudar temas e fenômenos relacionados à área de conhecimento. Esse grupo mantinha encontros quinzenais, no contraturno das aulas curriculares.

Coletivamente discutiu-se, estudantes e professoras, as expectativas em relação ao grupo e definiu-se a adoção de uma obra base, na ocasião um livro de divulgação científica, Os botões de Napoleão: as 17 moléculas que mudaram o rumo da história. ${ }^{6}$ Optou-se por leituras coletivas, dialogadas e motivadoras de ações investigativas sobre os temas abordados.

Os encontros e atividades desenvolvidas aconteceram ao longo dos anos letivos, de 2008 a 2010. Nessa fase ocorreu a formação de um grupo de estudos sobre temas que envolviam as Ciências da Natureza, por meio de investigações planejadas e desen-

\footnotetext{
Cada programa de ICJ tem objetivos específicos, compreendendo: o Programa de Iniciação Científica Júnior - IC-Jr/ Faps (Fundações Estaduais de Amparo à Pesquisa), o Programa de Iniciação Científica da Olimpíada Brasileira de Matemática das Escolas Públicas - PIC-OBMEP, e o Programa Institucional de Bolsas de Iniciação Científica para o Ensino Médio - Pibic-EM.

6 LE COUTEUR, P.; BURRESON, J. Os botões de Napoleão: as 17 moléculas que mudaram a história. Rio de Janeiro: Jorge Zahar Ed., 2006.
} 
volvidas por todos, não havendo hierarquia e nem pré-requisitos. A interrupção das atividades deu-se pela indisponibilidade das professoras em razão do plano de aulas definido para o período.

No ano de 2013 uma das professoras já envolvida no grupo anterior, foi procurada por duas estudantes, que cursavam o 3o ano do EM, na intenção de estruturarem um projeto para o Prêmio Jovem Cientista (PJC) instituído pelo CNPq, em 1982, que abordava naquela versão (27ạ edição) o tema "Água: desafios da sociedade". Retomaram-se os encontros, sem um cronograma pré-definido: o objetivo era desenvolver a ideia das estudantes, cumprindo as exigências do PJC.

Acompanhando a movimentação das estudantes em 2013, outros alunos do colégio, que cursavam o 20 ano do EM, motivaram-se a participar do PJC, em 2014. Naturalmente, seis estudantes, cursando o 20 e 30 ano do EM, propuseram encontros periódicos e investigações acerca do tema referente a 28 a edição do PJC, "Segurança alimentar e nutricional".

Semanalmente, no contraturno das aulas curriculares, estudantes e professora de Biologia reuniam-se para pensar, planejar e desenvolver ações de investigação sobre o tema. No decorrer das investigações identificou-se a possibilidade de planejar e desenvolver pesquisa aplicada. Foi quando iniciaram-se os diálogos com a gestão escolar e institucional para oficialização do apoio quanto a recursos de diferentes naturezas, de modo a iniciar e viabilizar a pesquisa científica e aplicada pelos estudantes da Educação Básica.

Em 2015, já com resultados da pesquisa aplicada desenvolvida, institucionalizou-se um grupo que, por influência do contexto universitário, denominou-se Grupo Estudantil em Iniciação Científica (Geic), nome e logotipo sugerido e votado pelos 12 alunos (do 1 을 3 o ano do EM) participantes. O Grupo foi cadastrado no CNPq e certificado pela Instituição, com, inicialmente, três linhas de pesquisa (Alimentação, Sustentabilidade e História da Ciência).

Desde então, os estudantes, do 8 ㅇ ano EFII ao 30 ano EM (todos, em suas turmas escolares) são convidados, no início do ano letivo, a participarem dos encontros que acontecem semanalmente no contraturno das aulas curriculares. Organizam-se em pequenos grupos por afinidade entre os participantes ou em relação ao tema pesquisado, que também é definido por eles - a partir de uma curiosidade ou problema real da sociedade em que estão inseridos. Os participantes permanecem no grupo o tempo que definirem, tendo liberdade para se afastar quando desejarem.

Entre as rotinas estabelecidas no grupo cabe citar a elaboração do Currículo Lattes por todos os estudantes e professores envolvidos nas pesquisas, por meio do qual são vinculados junto ao CNPq, a elaboração de um "Diário de Bordo" (OLIVEIRA; GEREVINI; STROHSCHOEN, 2017), no qual são registradas todas as ideias e relatadas todas as ações realizadas, propostas de pesquisa, atividades desenvolvidas e/ou resultados já obtidos para o grande grupo (o coletivo participa de todas as pesquisas desenvolvidas), assim como a escrita para publicação e a participação em eventos científicos. 
O Geic inicia o ano de 2019 com seis linhas de pesquisa cadastradas: História da Ciência, Sustentabilidade, Saúde, Alimentação, Escrileituras e Engenharias, 32 estudantes, do 8 ano EFF ao 3을 ano e 3 professores disciplinares (esses constituem-se os professores-orientadores) participantes. A coordenação do grupo e das atividades desenvolvidas está a cargo de um dos professores envolvidos.

As linhas de pesquisa vão sendo estruturadas a partir das proposições de projetos. No momento, as seis linhas de pesquisa, contam com o desenvolvimento de 11 projetos, para os quais os estudantes estão organizados em pequenos grupos, desde investigações individuais a grupos compostos por seis participantes.

Quadro 1 - Relação das Linhas de Pesquisa e seus Respectivos Objetivos e Projetos

\begin{tabular}{|c|c|c|}
\hline Linhas de Pesquisa & Objetivos & Projetos \\
\hline História da Ciência & $\begin{array}{l}\text { * Elucidar a natureza da Ciência assim como } \\
\text { episódios que ocorreram em determinado } \\
\text { espaço e tempo e que contribuíram para o } \\
\text { desenvolvimento científico. } \\
\text { * Produzir materiais didáticos e de } \\
\text { divulgação científica. }\end{array}$ & $\begin{array}{l}\text { * Pioneirismo científico } \\
\text { da região do Alto Vale do } \\
\text { Itajaí - SC. }\end{array}$ \\
\hline Sustentabilidade & $\begin{array}{l}\text { Investigar situações reais que promovam a } \\
\text { melhoria de vida das pessoas, qualificando } \\
\text { escolhas, respeitando e valorizando os } \\
\text { recursos naturais, bem como contribuindo } \\
\text { para a construção de uma sociedade mais } \\
\text { saudável, justa e solidária. }\end{array}$ & $\begin{array}{l}\text { * Sementes de imbuia.** } \\
\text { * A caatinga a partir de } \\
\text { olhares catarinenses. } \\
\text { * Avaliação da qualidade } \\
\text { do ar em Santa Catarina. }\end{array}$ \\
\hline Saúde & $\begin{array}{l}\text { Investigar processos e situações que } \\
\text { contribuam para a qualificação da saúde } \\
\text { humana e animal, bem como para a } \\
\text { compreensão das mesmas pelas pessoas. }\end{array}$ & $\begin{array}{l}\text { * Bulimia e anorexia. } \\
\text { * Síndrome de Marfan.** } \\
\text { * Fitoterapia em animais } \\
\text { de grande porte. } \\
\end{array}$ \\
\hline Alimentação & $\begin{array}{l}\text { Investigar questões que promovam a } \\
\text { qualificação da alimentação. }\end{array}$ & $\begin{array}{l}* \quad \text { Enriquecimento } \\
\text { nutricional de alimentos } \\
\text { vegetais pelo uso de pó } \\
\text { de rocha. }\end{array}$ \\
\hline Escrileituras & $\begin{array}{l}\text { Qualificar a leitura e a escrita das pessoas } \\
\text { a partir da vida. }\end{array}$ & * Ler e escrever o quê?** \\
\hline Engenharias & $\begin{array}{l}\text { Investigar situações reais que envolvam a } \\
\text { construção do mundo e o que há nele para } \\
\text { o seu progresso e de seus habitantes. }\end{array}$ & $\begin{array}{l}\text { * Dispositivo para veículos } \\
\text { de carga em sobrepeso. } \\
\text { * Órtese para fratura de } \\
\text { pé e tornozelo humano. }\end{array}$ \\
\hline
\end{tabular}

** São projetos finalizados ou desativados; os demais encontram-se em andamento.

Fonte: Autores (2019). Elaborado de acordo com o cadastro no diretório de Grupos do CNPq.

Os encontros semanais acontecem em uma sala com toda infraestrutura necessária, numa disposição que conta com mesas e bancadas, armários e prateleiras para colocação dos materiais; é um espaço compartilhado com o curso de Arquitetura, constituindo-se num ateliê de design. Cada tema investigado que exija condições específicas de exequibilidade, no entanto, estas serão mediadas pelos professores-orientadores que direcionarão e/ou acompanharão os estudantes nos laboratórios experimentais, de informática, visitas a campo, buscarão as condições necessárias para o desenvolvimento das etapas previstas. 
Os egressos não participam fisicamente dos encontros, mas todos continuam direta ou indiretamente presentes propondo pesquisas no Geic; participam virtualmente ou apresentam-se nos encontros em intervalos de tempo variados.

Metodologicamente, variados trabalhos já foram desenvolvidos, tanto quanti quanto qualitativos, enquadrando-se em pesquisas bibliográficas, documentais, estudos de caso, pesquisa-ação, todos de diferentes naturezas.

O trabalho desenvolvido até o momento representa um fenômeno pedagógico interessante e envolvente, o qual indica a necessidade de novas investigações, fundamentais para a lucidez de sua continuação, reestruturação e reprodução em diferentes instituições escolares.

\section{METODOLOGIA}

Esta pesquisa caracteriza-se como descritiva, de cunho qualitativo, uma vez que busca responder questões muito particulares. Conforme Minayo (2004), ela trabalhará com significados, motivos, aspirações, crenças, valores e atitudes, referindo-se a um espaço próprio nas relações, processos e fenômenos estabelecidos, os quais não podem ser quantificados. Destaca também Triviños (1987, p. 128) que a pesquisa qualitativa é essencialmente descritiva, pois "[...] as descrições dos fenômenos estão impregnadas dos significados que o ambiente lhes outorga, e como aquelas são produto de uma visão subjetiva, rejeitam toda expressão quantitativa, numérica, toda medida".

$\mathrm{O}$ trabalho foi realizado por meio da análise de documentos relativos às pesquisas desenvolvidas até o momento sobre a IC (documentos oficiais e publicações científicas), bem como documentos referentes à instituição que sedia o Geic, caracterizando uma pesquisa bibliográfica.

A pesquisa bibliográfica estuda e analisa documentos que são fontes secundárias de domínio científico (SÁ-SILVA; ALMEIDA; GUINDANI, 2009), sendo "[...] sua principal finalidade o contato direto com documentos relativos ao tema em estudo" (KRIPKA; SHELLER; BONOTTO, 2015, p. 244).

A revisão da literatura foi feita nas bases de dados SciELO e Education Resources Information Center, e por meio do metabuscador Portal de Periódicos da Capes, utilizando os seguintes descritores: Iniciação Científica, Educação Básica e Ensino Médio; além de livros e sites oficiais e institucionais. As buscas foram realizadas de julho de 2017 a abril de 2018.

Também foram realizadas observações participantes (VIANNA, 2007; CARMO; FERREIRA, 2008) por uma das autoras deste artigo e de oito estudantes atuais, participantes do Geic (identificados por números de 1 a 8 ), na intenção de verificar suas percepções em relação às contribuições do grupo para sua formação. Foram selecionados, privilegiando alunos com, no mínimo, seis meses de frequência, por já terem uma vivência da rotina dos trabalhos no grupo. À época das observações os estudantes tinham de 13 a 17 anos de idade e participavam de projetos de pesquisa distintos.

Considerando aspectos relevantes acerca da observação participante, assinalados por Carmo e Ferreira (2008), cabe assinalar que ela foi utilizada neste trabalho como ferramenta exploratória, coletando os dados (narrativas dos estudantes) por meio de 
áudio disponibilizado explicitamente no espaço em que os vários grupos de pesquisa trabalhavam, ao longo de seis encontros durante o primeiro semestre de 2018. Os autores asseveram que

há muito utilizada [...] em estudos sobre pequenas comunidades, a observação participante tem vindo a ser cada vez mais usada em trabalhos de natureza sociológica, interdisciplinar ou em antropologia das comunidades complexas, quer como ferramenta exploratória quer como técnica principal de coleta de dados, quer ainda como instrumento auxiliar de pesquisas de natureza quantitativa (CARMO; FERREIRA, 2008, p. 122).

As narrativas dos estudantes, como dados coletados, foram tratadas qualitativamente pela análise de conteúdo (MORAES, 1999; FRANCO, 2018). Tal análise constitui-se de cinco etapas: a) preparação das informações (as narrativas foram identificadas e o material codificado); b) unitarização (os áudios foram transcritos, as narrativas lidas e definidas para classificação - unidades de análise); c) categorização (as narrativas foram agrupadas de acordo com os aspectos de aproximação e afastamento das proposições do Geic em relação a IC, resultantes da pesquisa bibliográfica); d) descrição (trechos das narrativas ratificam as unidades de análise, buscando expressar seus significados) e e) interpretação (permitiu a construção de novos sentidos, ampliando a compreensão dos dados).

\section{A MIRAGEM SOBRE AS NARRATIVAS E O DIÁLOGO COM OS AUTORES E INTERLOCUTORES}

$\mathrm{Na}$ análise das narrativas dos estudantes, por análise de conteúdo, na etapa de unitarização, os trechos apresentados evidenciam as unidades de análise como sendo os distanciamentos e aproximações do Geic com a IC institucionalizada no Brasil, definidas a partir da pesquisa bibliográfica e, emergindo na etapa de categorização, as categorias apresentadas no Quadro 2.

Quadro 2 - Unidades de Análise e Categorias Referentes à Análise de Conteúdo das Narrativas dos Estudantes Participantes Observados

\begin{tabular}{|c|c|}
\hline Unidades de Análise & Categorias de Análise \\
\hline \multirow{3}{*}{$\begin{array}{c}\text { Distanciamentos do Geic com princípios da IC } \\
\text { institucionalizada. }\end{array}$} & Metodologia de trabalho \\
\hline & Espaços de pesquisa \\
\hline & Caráter eletivo de participação \\
\hline \multirow{2}{*}{$\begin{array}{l}\text { Aproximações do Geic com princípios da IC } \\
\text { institucionalizada. }\end{array}$} & Aspectos pedagógicos \\
\hline & Protagonismo do estudante \\
\hline
\end{tabular}

Fonte: Autores (2019).

Um distanciamento identificado entre o Geic e as demais proposições de IC foi referente à prática educativa proposta no Geic, que é construída no coletivo, por todos os sujeitos envolvidos, não sendo um papel exercido exclusivamente pelo professor-orien- 
tador e/ou pesquisador. Como apresenta Ferreira (2003, p. 117), “[...] são os próprios pesquisadores que tomam a frente do processo de construção de práticas educativas para marcar suas posições no debate sobre a iniciação científica no Ensino Médio".

Os professores-orientadores no Geic são licenciados em suas áreas de formação inicial, o que lhes atribui a compreensão do processo pedagógico, uma vez que são profissionais da educação, distanciando a configuração dos profissionais envolvidos nos diversos programas de IC institucionalizados, sendo esses, na maioria dos casos, técnicos das áreas pesquisadas sob sua orientação.

Além da característica dos professores-orientadores, também o tempo disponibilizado a essa tarefa, a quantidade de horas de orientação recebidas pelos estudantes do Geic é proporcionalmente maior que as horas disponibilizadas nos programas de IC, tanto Júnior quanto para o Ensino Superior.

Em relação à orientação dos trabalhos, explicitam Sousa e Filipecki (2017, p. 78) que os estudos mais recentes acerca da IC evidenciam que a orientação "[...] consolidou-se como um modelo denominado 'cascata', em que o pesquisador sênior orienta o doutorando e o pós-graduando, o pesquisador júnior, o estudante de graduação e o estudante de graduação orienta o estudante de ensino médio".

Nesse sentido, a orientação no Geic ocorre sempre pelos professores disciplinares do EM, esses indicarão e mediarão a participação de outros profissionais, ligados à educação ou não, de acordo com as limitações conceituais e técnicas do projeto em desenvolvimento.

A característica dos professores-orientadores do Geic contribui diretamente para a efetivação de uma prática interdisciplinar (ZUCOLOTTO et al., 2004; THIESEN, 2008; FURLANETTO, 2014); aproximando o Grupo da proposição de IC institucionalizada, uma vez que se fazem necessários diálogos com diferentes profissionais competentes nas áreas de desenvolvimento das pesquisas propostas.

Os professores-orientadores acreditam que a IC é uma "arte prática", que se aprende pela imitação e experiência (FERREIRA, 2003; FILIPECKI; BARROS; ELIA, 2006), enquanto que no Geic acredita-se na aprendizagem pelo protagonismo do estudante na investigação a realizar-se, sendo, em alguns casos, muito mais teórica que prática, propriamente dita, de modo que todos os envolvidos aprendem juntos.

[...] a liberdade para desenvolver o raciocínio e mover-se livremente em conduta própria orientados segundo as necessidades que sentimos, acaba sendo um dos fatores dos bons resultados (Estudante 1). ${ }^{7}$

[...] apresentando pontos positivos do grupo, como a metodologia proposta, a autonomia para realizar a pesquisa/projeto (Estudante 2).

O Geic proporciona experiências que antes não eram vistas como possíveis, a pesquisa coletiva, [...] as vivências de estar dentro de um grupo que desfruta dos mesmos objetivos [...] a própria metodologia do grupo científico (Estudante 3).

Neste artigo, as falas dos estudantes estão grafadas em itálico para distingui-las das contribuições dos teóricos que dão apoio ao texto. Para preservar as identidades dos estudantes, suas falas estão codificadas sob a forma Estudante 1... 
No Geic [...] a liberdade de trabalho, liberdade para montar o grupo, [...] diversidade (Estudante 8).

Considerando que há diferenças entre as concepções e as ênfases de IC (SOUSA; FILIPECKI, 2017), as proposições do Geic aproximam-se e distanciam-se dos demais programas e proposições de IC para a Educação Básica, tanto nas concepções quanto nas ênfases. O distanciamento é maior em relação às concepções que, de um modo geral, foram apresentadas no decorrer do trabalho, sendo comum nas experiências citadas a formação de uma nova geração de pesquisadores, atribuindo um caráter muitas vezes elitista para seus participantes (centrado no desempenho acadêmico, por exemplo) e a relação direta do fazer pesquisa ligado ao espaço do laboratório.

[...] aprender coisas novas, experiências, visitas a novos espaços, pesquisas sobre assuntos que tivermos mais curiosidade, ir a palestras e fazê-las também, [...], aprender mais e ajudar os outros de diferentes formas [...] tudo isso é o Geic (Estudante 6).

Em relação às ênfases atribuídas aos programas e proposições de IC, o Geic aproxima-se, e muito, daqueles que valorizam os aspectos pedagógicos, "[...] integrar teoria e prática, aumentar a sociabilidade, permitir o desenvolvimento de qualidades/habilidades para a futura vida profissional - quer seja na pesquisa ou em outra atividade profissional" (SOUSA; FILIPECKI, 2017, p. 79), entre outros, considerando desde a definição do problema, os percursos metodológicos, a coleta e análise dos dados e a divulgação dos mesmos, uma vez que é o estudante quem protagoniza todas as etapas.

No Geic podemos escolher o tema de nosso interesse e fazer atividades fora do comum [...]. O Geic não é extremamente formal, estamos orientados de forma livre (Estudante 4).

Eu gosto de participar do Geic, pelo fato de nossas pesquisas, descobertas e aprofundamentos alimentarem minha curiosidade [...].(Estudante 5).

Venho aqui para pesquisar, estudar e ao mesmo tempo me divertir com o grupo. (Estudante 7).

Nas narrativas dos estudantes evidencia-se ${ }^{8}$ o seu protagonismo e os aspectos pedagógicos e metodológicos que norteiam as ações desenvolvidas, além do sentimento de pertencimento, atribuindo o caráter colaborativo ao fazer científico.

Lançando o olhar para a definição do problema a ser investigado, uma evidência que emerge das ênfases do Geic é a valorização das ideias trazidas e compartilhadas pelos estudantes.

Todas as questões são propostas por eles, apresentadas ao coletivo e por todos, definido seu percurso investigativo; caso não seja exequível no momento de sua exposição, essas são encaminhadas para a "cápsula de latência" ${ }^{9}$ e de lá são retiradas quan-

\footnotetext{
3 A análise foi feita de acordo com a proposição da "Educação Baseada em Evidências" (OLIVEIRA, 2014, p. 26). 0 autor indica ser essa "[...] o novo nome de uma velha prática: a busca de argumentos racionais, com base científica, para promover uma educação de melhor qualidade".

9 A "cápsula de latência" consiste numa pasta onde as ideias são escritas pelos estudantes e lá arquivadas, permanecendo até tornarem-se questões de investigação.
} 
do possível de serem executadas, de maneira pura, constituindo um projeto em si ou acoplada, complementando outros projetos; "nenhuma ideia é perdida ou considerada absurda o suficiente para não ser considerada" (Estudante 6).

A ênfase na valorização das ideias dos estudantes no Geic passou a ser uma rotina e constitui um afastamento evidente das demais proposições de IC, aqui definidas como "Programas de Pesquisa Científica", relacionando-os com a ideia da "Metodologia dos Programas de Pesquisa Científica" (MPPC), enunciada por Lakatos.

Ao considerar o Geic um Programa de Pesquisa Científica e assim também cada projeto de pesquisa em si, entende-se o desenvolvimento do Programa a partir de uma sucessão de modelos crescentes em complexidade, que procura cada vez mais aproximar-se da realidade. Segundo Lakatos (1989):

Um modelo é um conjunto de condições iniciais (possivelmente junto com algumas teorias observacionais) que se sabe que deve ser substituído durante o ulterior desenvolvimento do programa, e que inclusive se sabe como deve ser substituído (em maior ou menor medida) (p. 70).

A ênfase nas ideias dos estudantes permite reflexões importantes acerca da natureza da ciência, uma vez que oportuniza a eles perceberem que o conhecimento científico é uma construção humana intencional e que esse ato de construção envolve a imaginação, a intuição, a razão, entre outros tipos de influências, princípios que derivam da epistemologia racionalista de Popper e Lakatos (SILVEIRA, 1996; GUIMARÃES et al., 2017).

\section{O HORIZONTE DO OLHAR - AS CONSIDERAÇÕES FINAIS}

O contexto de espaços privilegiados, como é o caso do Geic, vem apontar para uma possibilidade de superação na formação dos estudantes em um ensino voltado para a educação científica que contempla reflexões sobre a importância dos processos investigativos.

Acredita-se que despender esforços para um ensino baseado na pesquisa deve acontecer desde os anos iniciais da Educação Básica, em particular no EF e EM, uma vez que oportuniza ao estudante o desenvolvimento do processo investigativo, assim como a comunicação dos resultados e de suas aplicações.

A IC na Educação Básica desafia o pensar sobre a importância da construção de um processo educativo contextualizado, emergindo uma significativa contribuição para o (re)pensar da pesquisa como componente curricular e, por conseguinte, a formação docente.

É possível que o docente da Educação Básica, constituindo-se pesquisador, seja o orientador das pesquisas investigadas desenvolvidas pelos estudantes. Fazendo a pesquisa na e a partir da escola, outras instituições de ensino e pesquisa seriam interlocutores no diálogo estabelecido, aproximando-as, assim como seus agentes, oportunizando espaços para trocas e novos projetos. 
Considerando outros programas, resguardadas as especificidades, o Geic baseia-se em propostas metodológicas diferentes do ensino regular, facultando o contato com teorias e práticas até então reservadas ao Ensino Superior e/ou fazeres pedagógicos não formais, proporcionando aos sujeitos novas habilidades e atitudes. As relações são marcadas por acordos sociais, tornam-se democráticas e construídas coletivamente.

A valorização dos aspectos pedagógicos, ao considerar uma prática investigativa e seus fazeres, contribui para a realização das pesquisas planejadas e efetivamente para o processo formativo num viés integral, possibilitando a compreensão do processo de desenvolvimento do conhecimento, do pensamento crítico e da autonomia, o estímulo da criatividade e da autoestima, a reforma efetiva de atitudes mais cidadãs.

A robustez das pesquisas desenvolvidas pelos estudantes do Geic e o sentido aplicado a elas subsidiam situações e problemas reais da sociedade em que estão inseridos, incitando-os a dialogarem com outras realidades, o que exige dos envolvidos, professores-orientadores, técnicos e gestores, mais recursos tanto físicos quanto financeiros.

Entre os questionamentos que emergem desse estudo está o como proporcionar a todos os estudantes do EM a experiência de fazer pesquisa num grupo de IC, considerando todas as variáveis que os envolvem, ou não, em tal atividade.

O estudo dos desdobramentos da participação qualificada dos estudantes no Geic como proposta de pesquisa apresenta distanciamentos e aproximações dos programas e proposições da IC institucionalizada no Brasil.

\section{REFERÊNCIAS}

AGUIAR, L. C. C. O perfil da iniciação científica no Instituto de Biofísica Carlos Chagas Filho e no Departamento de Bioquímica Médica da Universidade Federal do Rio de Janeiro. 1997. 119f. Dissertação (Mestrado) - UFRJ, Centro de Ciências da Saúde, Instituto de Ciências Biomédicas, Rio de Janeiro, 1997.

ARANTES, S. L. F.; PERES, S. O. Programas de iniciação científica para o Ensino Médio no Brasil: educação científica e inclusão social. Pesquisas e Práticas Psicossociais, São João Del-Rei, 10(1), jan./jun. 2015.

BARDIN, Laurence. Análise de conteúdo. São Paulo: Edições 70, 2011.

BARIANI, I. C. D. Estilos cognitivos de universitários e iniciação científica. 1998. 170f. Tese Doutorado) Universidade Estadual de Campinas, Faculdade de Educação. Programa de Pós-Graduação em Educação, Campinas, SP, 1998.

BARROS, V. F. A.; SOUZA, M. A. R.; MACHADO, S.S. Portal de Periódicos da Capes: a importância da investigação científica na iniciação científica. Cadernos de Educação, Tecnologia e Sociedade, v. 3, n. 1, p. 47-53, 2012.

BAZIN, M. J. O que é iniciação científica. Revista de Ensino de Física, São Paulo, v. 5, n. 1, p. 81-88, 1983.

BRASIL. Diretrizes Curriculares Nacionais Gerais da Educação Básica. Brasília: Ministério da Educação; Secretaria de Educação Básica; Diretoria de Currículos e Educação Integral, 2013. 562p. Disponível em: http://portal.mec.gov.br/index.php?option=com_docman\&task=doc_details\&gid=13448\&ltemid=122. Acesso em: 23 ago. 2016.

BRASIL. Resolução CNE/CP 002/2012. Define as Diretrizes Curriculares Nacionais para o Ensino Médio. Diário Oficial [da] República Federativa do Brasil. Brasília, DF, 31 de jan. de 2012. Disponível em: http:// portal.mec.gov.br/index.php?option=com_docman\&view=download\&alias=9917-rceb002-12-1\&Itemid=30192. Acesso em: 29 out. 2016.

BRASIL. Lei 1.310 de 10 de janeiro de 1951. Cria o Conselho Nacional de Pesquisa e dá outras providências. Diário Oficial [da] República Federativa do Brasil. Brasília, DF, 16 jan. 1951. Disponível em: http:// www2.camara.leg.br/legin/fed/lei/1950-1959/lei-1310-15-janeiro-1951-361842-publicacaooriginal-1-pl. html. Acesso em: 24 jul. 2017. 
BREGLIA, V. L. A. A formação na graduação: contribuições, impactos e repercussões do PIBIC. Rio de Janeiro, 2002. 210f. Tese (Doutorado em Educação) - Pontifícia Universidade Católica do Rio de Janeiro. BRIDI, J. C. A. A iniciação científica na formação do universitário. 2004. 135f. Dissertação (Mestrado) Universidade Estadual de Campinas, Faculdade de Educação. Programa de Pós-Graduação em Educação, Campinas, SP, 2004.

BRIDI, J. C. A. A pesquisa nas universidades brasileiras: implicações e perspectivas. In: MASSI, L.; QUEIROZ, S. L. Iniciação científica [recurso eletrônico]: aspectos históricos, organizacionais e formativos da atividade no Ensino Superior brasileiro. São Paulo: Editora Unesp Digital, 2015.

CABRERO, R. C.; COSTA, M. P. R.; HAYASHI, M. C. P. I. Estudantes do Ensino Superior vivenciando ciência: efeitos na Pós-Graduação. In: SEMINÁRIO ESTADUAL DA ASSOCIAÇÃO NACIONAL DE POLÍTICA E ADMINISTRAÇÃO DE EDUCAÇÃO, 10., 2006, São Bernardo do Campo. Anais [...]. São Bernardo do Campo: Universidade Metodista de São Paulo, 2006. p. 1-10. V. I.

CACHAPUZ, A.; PRAIA, J.; JORGE M. Reflexão em torno de perspectivas do ensino das ciências: contributos para uma nova orientação escolar - ensino por pesquisa. Revista de Educação, v. IX, n. 1, p. 69-79, 2000.

CARMO, H.; FERREIRA, M. M. Metodologia da investigação: guia para auto-aprendizagem. Lisboa, PT: Universidade Aberta, 2008.

CARVALHO, A. G. O Pibic e a difusão da carreira científica na universidade brasileira. 2002. 159 f. Dissertação (Mestrado) - UNB, Programa de Pós-Graduação em Sociologia, Brasília, 2002.

COELHO FILHO, M. S.; GONZAGA, A. M. Iniciação científica na formação de professores: contribuições epistemológicas. Curitiba: Appris, 2013.

DEMO, P. Pesquisa e informação qualitativa: aportes metodológicos. Campinas: Editora Papirus, 2001.

DOURADO, L. F.; OLIVEIRA, J. F. A Qualidade da educação: perspectivas e desafios. Cad. Cedes, v. 29, n. 78, p. 201-215, maio/ago. 2009.

ERDMANN, A. L. et al. Vislumbrando a iniciação científica a partir das orientadoras bolsistas da enfermagem. Rev. Bras. Enferm, 64 (2), p. 261-267, 2011.

FERREIRA, C. A. Concepções da Iniciação Científica no Ensino Médio: uma proposta de pesquisa. TrabaIho, Educação e Saúde, 1 (1), p. 115-130, 2003.

FERREIRA, C. A. O Programa de Vocação Científica da Fundação Oswaldo Cruz: fundamentos, compromissos e desafios. In: FERREIRA, C. A.; PERES, S. O.; BRAGA, C. N.; CARDOSO, M. L. M. (Org.). Juventude e iniciação científica: políticas públicas para o Ensino Médio. Rio de Janeiro: EPSJV; UFRJ, 2010.

FERREIRA, M. S. Iniciação científica no Ensino Médio: reflexões a partir do campo do currículo. In: FERREIRA, C. A.; PERES, S. O.; BRAGA, C. N.; CARDOSO, M. L. M. (Org.). Juventude e iniciação científica: políticas públicas para o ensino médio. Rio de Janeiro: EPSJV; UFRJ, 2010.

FILIPECKI, A.; BARROS, S. S.; ELIA, M. F. A visão dos pesquisadores-orientadores de um programa de vocação científica sobre a Iniciação Científica de estudantes de Ensino Médio. Ciência \& Educação, v. 12, n. 2, p. 199-227, 2006.

FIOR, C. A. Contribuições das atividades não obrigatórias na formação universitária. 2003. 122f. Dissertação (Mestrado) - Universidade Estadual de Campinas, Faculdade de Educação, Programa de Pós-Graduação em Educação, Campinas, SP, 2003.

FRANCO, M. L. P. B. Análise de conteúdo. Brasília: Plano Editora, 2018.

FURLANETTO, E. C. Interdisciplinaridade: uma epistemologia de fronteiras. In: ROSITO-BERKENBROCK, M. M. (org.). Interdisciplinaridade e transdisciplinaridade: políticas e práticas de formação de professores. Rio de Janeiro: Wak Editora, 2014.

GADOTTI, M. Qualidade na educação: uma nova abordagem. Congresso de Educação Básica: qualidade na aprendizagem. Florianópolis, 2013. Disponível em: http://www.pmf.sc.gov.br/arquivos/arquivos/pdf/14_02_2013_16.22.16.85d3681692786726aa2c7daa4389040f.pdf. Acesso em: 12 fev. 2018.

GUIMARÃES, G. L. et al. A contribuição de Imre Lakatos para a ANÁLISE EPISTEMOLÓGICA do Programa Brasileiro de Pós-Graduação em Enfermagem. Texto Contexto Enfermagem, 26 (1): e384001, 2017. Disponível em: http://www.scielo.br/pdf/tce/v26n1/pt_0104-0707-tce-26-01-e384001.pdf. Acesso em: 17 ago. 2018.

HECK, T. G. et al. Iniciação científica no Ensino Médio: um modelo de aproximação da escola com a universidade por meio do método científico. Revista Brasileira de Pós-Graduação, v. 8, n. 2, cap. 4, 2012. Disponível em: http://ojs.rbpg.capes.gov.br/index.php/rbpg/article/view/24. Acesso em: 9 jun. 2018.

KRIPKA, R. M. L.; SHELLER, M.; BONOTTO, D. L. Pesquisa documental: considerações sobre conceitos e características na Pesquisa Qualitativa. Investigação Qualitativa em Educação, Atas CIAIQ, v. 2, p. 243-247, 2015. 
LAKATOS, I. La metodología de los programas de investigación científica. Madrid: Alianza, 1989.

LATOUR, B.; WOOLGAR, S. A vida de laboratório: a produção dos fatos científicos. Rio de Janeiro: Relume Dumará, 1997.

LE COUTEUR, P.; BURRESON, J. Os botões de Napoleão: as 17 moléculas que mudaram a história. Rio de Janeiro: Jorge Zahar Ed., 2006.

MARANHÃO, T. P. A. Avaliação de impacto da Olimpíada Brasileira de Matemática nas Escolas Públicas (OBMEP - 2005-2009). In: Avaliação do impacto da Olimpíada Brasileira de Matemática nas escolas públicas. Brasília: Centro de Gestão e Estudos Estratégicos, 11 jul. 2011. (Série Documentos Técnicos).

MARTINS, R. C. R.; MARTINS, C. B. Programas de melhoria e inovação no ensino de Graduação. Estudos e Debates: uma Política de Ensino Superior, Brasília, v. 20, p. 189-221, 1999.

MARTINS, G. M. M. O que queremos da escola média? A perspectiva de pesquisadores, professores e estudantes do Ensino Médio. Espacios en Blanco - Serie Indagaciones, n. 22, p. 143-164, 2012.

MASSI, L.; QUEIROZ, S. L. Estudos sobre Iniciação Científica no Brasil: uma revisão. Cadernos de Pesquisa, v. 40, n. 139, p. 173-197, 2010.

MASSI, L.; QUEIROZ, S. L. Investigando processos de autoria na produção do relatório de iniciação científica de um graduando em química. Ciência \& Educação, v. 18, n. 2, p. 271-290, 2012.

MASSI, L.; QUEIROZ, S. L. A perspectiva brasileira da iniciação científica: desenvolvimento e abrangência dos programas nacionais e pesquisas acadêmicas sobre a temática. In: MASSI, L.; QUEIROZ, S. L. Iniciação científica [recurso eletrônico]: aspectos históricos, organizacionais e formativos da atividade no Ensino Superior brasileiro. São Paulo: Editora Unesp Digital, 2015.

MAZON, L.; TREVIZAN, M. A. Fecundando o processo da interdisciplinaridade na iniciação científica. Revista Latino-Am. Enfermagem, 9 (4), p. 83-87, 2001.

MINAYO, M. C. S. Ciência, técnica e arte: o desafio da pesquisa social. In: MINAYO, M. C. S. (org.). Pesquisa social: teoria, método e criatividade. Petrópolis: Vozes, 2004. p. 9-28.

MORAES, G. C. et al. A iniciação científica júnior: o que dizem os alunos. [Abstract]. CONGRESSO NACIONAL DE EDUCAÇÃO, 11., 2013, Anais [...]. Curitiba, PR, 2013.

MORAES, R. Análise de conteúdo. Revista Educação, 22 (37), p. 7-32, 1999.

MORAES, R.; RAMOS, M. G.; GALIAZZI, M. C. A epistemologia do aprender no educar pela pesquisa em Ciências: alguns pressupostos teóricos. In: MORAES, R.; MANCUSO, R.(org.). Educação em ciências: produção de currículos e formação de professores. ljuí: Editora Unijuí, 2004.

NEVES, R. M. C. Lições da iniciação científica ou a pedagogia do laboratório. História, Ciências, Saúde, Manguinhos, v. VII(3), p. 71-79, 2001.

OHAYON, P. et al. Iniciação científica: uma metodologia de avaliação. Ensaio: Aval. Pol. Públ. Educ., v. 15, n. 54, p. 127-144, 2007.

OLIVEIRA, A. M.; GEREVINI, A. M.; STROHSCHOEN, A. A. G. Diário de bordo: uma ferramenta metodológica para o desenvolvimento da alfabetização científica. Revista Tempos e Espaços em Educação, v. 10, n. 22, p. 119-132, maio/ago. 2017.

OLIVEIRA, F. P. Z. Pactos e impactos de iniciação científica na formação de estudantes do Ensino Médio. 2017. 343f. Tese (Doutorado) - Universidade Federal de Santa Catarina, Programa de Educação Científica Tecnológica, Florianópolis, SC, 2017.

OLIVEIRA, J. B. A. Educação baseada em evidências. In: OLIVEIRA, J. B. A (org.). Educação baseada em evidências. Brasília, DF: Instituto Alfa e Beto, 2014. p. 10-30. (Coleção IAB de Seminários Internacionais).

PIRES, R. C. M. A contribuição da iniciação científica na formação do aluno de graduação numa universidade estadual. 2002. 203f. Dissertação (Mestrado] - Salvador, BA: Ufba, Faculdade de Educação, Programa de Pós-Graduação em Educação, 2002.

QUEIROZ, S. L.; ALMEIDA, M. J. P. M. Do fazer ao compreender ciências: reflexões sobre o aprendizado de alunos de Iniciação Científica em Química. Ciência e Educação, v. 10, n. 1, p. 41-53, 2004.

ROSA, M. B. A inclusão da instituição escola na cultura digital e a construção de novos paradigmas a partir da iniciação científica na educação básica. 2013. 252f. Tese (Doutorado) - Universidade Federal do Rio Grande do Sul, Programa de Pós-graduação em Informática na Educação, Porto Alegre. RS, 2013.

SÁ-SILVA, J. R.; ALMEIDA, C. D.; GUINDANI, J. F. Pesquisa documental: pistas teóricas e metodológicas. Revista Brasileira da História \& Ciências Sociais, ano I, n. 1, jul. 2009. 
SANTOS, G. L.; ABREU, P. H. Avaliação do impacto da Olimpíada Brasileira de Matemática nas Escolas Públicas (OBMEP): explicitação de condições de sucesso em escolas bem sucedidas. In: Avaliação do impacto da Olimpíada Brasileira de Matemática nas escolas públicas. Brasília: Centro de Gestão e Estudos Estratégicos, 11 jul. 2011. (Série Documentos Técnicos).

SILVA JUNIOR, M. F. et al. Iniciação científica: percepção do interesse de acadêmicos de odontologia de uma universidade brasileira. Saúde Soc. São Paulo, v. 23, n. 1, p. 325-335, 2014.

SILVEIRA, F. L. A Metodologia dos programas de pesquisa: a epistemologia de Imre Lakatos. Cad. Cat. Ens. Fis., v. 13, n. 3, p. 219-230, 1996.

SOUSA, I. C. F.; FILIPECKI, A. T. P. Iniciação científica de estudantes de Ensino Médio: um olhar sobre esta formação em uma instituição de pesquisa biomédica brasileira. Luglio, n. 17, p. 74-95, 2017.

SOUZA, R. R. Letramentos e indícios de identidades em (trans)formação: atuação docente na iniciação científica no Ensino Médio Técnico Integrado. Recorte, v. 11, n. 1, p. 1-19, 2014.

TENÓRIO, M. P.; BERALDI, G. Iniciação científica no Brasil e nos cursos de medicina. Rev. Assoc. Med. Bras., 56 (4), p. 375-393, 2010.

THIESEN, J. S. A interdisciplinaridade como um movimento articulador no processo ensino-aprendizagem. Revista Brasileira de Educação, v. 13, n. 39, p. 545-598, 2008.

TRIVIÑOS, A. N. S. Introdução à pesquisa em ciências sociais: a pesquisa qualitativa em educação. São Paulo: Atlas, 1987.

VIANNA, H. M. Pesquisa em educação: a observação. Brasília: Liber Livro Editora, 2007. V. 5. (Série Pesquisa).

VILCHES, A. et al. Da necessidade de uma formação científica para uma educação para a cidadania. SIMPÓSIO DE PESQUISA EM ENSINO E HISTÓRIA DE CIÊNCIAS DA TERRA, 1., e SIMPÓSIO NACIONAL DE ENSINO DE GEOLOGIA, 3., 2007, Campinas. Anais [...]. Campinas. p. 421-426, 2007.

ZAKON, A. Qualidades desejáveis na iniciação científica. Ciência e Cultura-Revista da Sociedade Brasileira para o Progresso da Ciência, 41(9), p. 868-877, 1989.

ZUCOLOTTO, A. M. et al. Do nome das coisas à disciplina dos termos: O que sabemos? Integração, ano $\mathrm{X}$, n. 39, p. 321-332, 2004. 